\title{
AC 2008-2564: CLASSROOM TEACHING AIDS AND LABORATORY EXPERIMENTATION TO ENGAGE STUDENTS IN MATERIALS LEARNING
}

Stephan Durham, University of Colorado at Denver

Micah Hale, University of Arkansas

Seamus Freyne, Manhattan College 


\title{
Classroom Teaching Aids and Laboratory Experimentation to Engage Students in Materials Learning
}

\begin{abstract}
Most civil engineering programs require one course in materials and materials testing. These courses are designed to provide students with general knowledge of the production, properties, and behavior of common structural materials. Emphasis is often placed on the three predominately used materials: concrete, steel, and wood. This paper presents teaching aids and laboratory experiments that can be used as an effective method of introducing material properties and behavior to students. The authors have identified several analogies, in-class demonstrations, visual aids, and laboratory experiments that enhance the learning of structural materials. The "Hamburger Helper" analogy can be used to describe aggregate's function as economical filler in concrete as noodles (aggregates) are considerably cheaper than hamburger meat (cement) and can be used to produce a larger meal (concrete mixture) at a reduced cost. Cement hydration is often a difficult topic for students to understand. The reaction between water and cement can be demonstrated using a candy, the "Atomic Fireball." The heat liberation curve for cement hydration resembles the heat given off by an Atomic Fireball. The stress-strain curve for steel can be described as "Traffic Gridlock on an Interstate." The initial portion of the curve resembles slow moving traffic that produces large amounts of stress for drivers. This is followed by a point on the curve or location on the interstate when traffic speed increases resulting in decreased stress and much greater strain. This comparison continues through strain hardening until failure or the drivers reach their destination. Straws are an effective method of illustrating the structure of wood. Wood is composed of hollow tube-like cells that resemble a group of drinking straws. Laboratory experiments that examine the effects of water-to-cement ratio and curing environment on concrete compressive strength reinforce topics discussed in class lectures. Teaching aids and laboratory experiments are an effective method of demonstrating important concepts. The methods discussed in this paper have shown to engage students in the learning of structural materials.
\end{abstract}

\section{Introduction}

Many civil engineering curriculums require at least one course in construction materials. These classes provide students with the basic knowledge and understanding of the production, properties, testing, and behavior of common structural materials. A large emphasis is placed on concrete, steel, and wood due to their wide use and availability in the design and construction of structures. This paper presents teaching aids and laboratory experiments that have been used by the authors in their respective classes. These teaching resources have been found to be an effective and interesting method of introducing material properties and behavior to students. The resources identified in this paper include analogies, in-class demonstrations, visual aids, and laboratory experiments. Such resources discussed in this paper are used to explain the effects of 
aggregate shape on the properties of concrete, the use of aggregate in concrete, cement hydration, stress-strain behavior of steel, and the cellular structure of wood. The authors have received positive comments regarding the use of these teaching aids and experiments in class. Students often mention how these teaching resources reinforce the concepts discussed in class as well as creating more interest in course topics.

\section{Learning Styles for Engineering Students}

People learn in different ways. Learning styles are methods that people use to understand material. ${ }^{1}$ Learning styles include these types:

- Visual Learners-prefer pictures, charts, and demonstrations

- Aural Learners-prefer the use of sound and music

- Verbal Learners-prefer oral communication and writing

- Physical Learners-prefer physical movement and active learning

- Logical Learners-prefer logical reasoning and solving

- Social Learners-prefer working with other individuals

- Solitary Learners-prefer working individually

Studies summarized by P. Rosati have shown engineers to be active, sensing, visual, and sequential learners. ${ }^{2}$ Rosati recommends improved teaching in engineering related courses through more active, sensing, visual, and global teaching components. In addition, Rosati mentions that the most effective single improvement to engineering related courses is to include practical laboratory and design applications. Felder and Spurlin report a consistent pattern of learning style preferences for engineering students. ${ }^{3}$ In a comprehensive study consisting of multiple universities and consecutive years of sampling engineering students' learning preferences, Felder and Spurlin show that the majority of engineering students are active, sensing, visual, and sequential learners.

The previously mentioned studies reinforce the need to engage students in a dynamic, visual manner during course lectures. This paper describes several analogies, classroom demonstrations, visual aids, and laboratory experiments that create interest in class topics and provide a lasting memory of the subject being taught.

\section{Teaching Aids}

\section{$\underline{\text { Dice and Marble Analogy }}$}

The shape of aggregate particles directly impacts how the material will pack into a dense configuration. ${ }^{4}$ In addition, particle shape also affects the material's workability or placeability. Generally, there are five classifications of particle shape: angular, rounded, flaky, elongated, and flaky-elongated. Aggregate accounts for approximately $60-80 \%$ of concrete's volume and is typically an angular crushed stone or rounded gravel. Because aggregate shape affects the properties of concrete, the authors use the dice and marble analogy. This analogy compares the shape of dice and marbles to aggregates, Figure 1. Aggregate shape has a direct effect on the strength and workability of concrete. If the aggregate shape is round, typically the concrete will be more workable and easier to place. This is observed by using several marbles and rolling 
them on a table. If you rolled a pair of die on the same table, they do not move as easily resulting in less workability. Aggregate shape can affect the concrete compressive strength. Aggregates with an angular shape (dice) result in higher stability than aggregates with rounded shapes (marble).
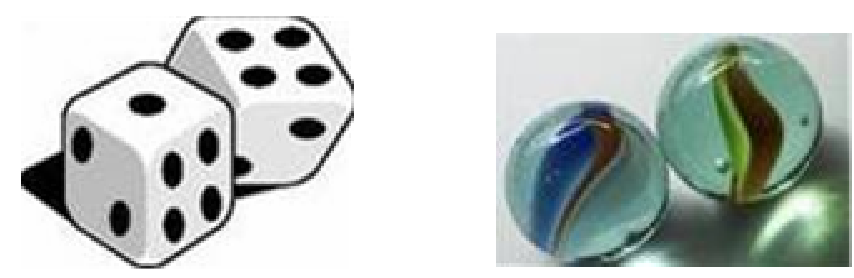

Figure 1. Comparison between Dice and Marbles ${ }^{5,6}$

Marbles can also be used to demonstrate the bulk density of aggregates. Aggregates with high bulk density have low voids content, which means less cement paste is needed to fill those voids. Concrete mixtures which contain aggregates with a high bulk density generally exhibit excellent durability. To learn about this concept, students can fill a jar, which represents a volume of concrete, with marbles of various sizes, which represent the aggregates. When the jar is full of marbles, the amount of voids can be determined by pouring water into the jar. Students will find that some blend of marble sizes yields the lowest voids content, not a uniform size of small marbles or a uniform size of large marbles.

\section{Hamburger Helper Analogy}

In the lecture that introduces concrete, the author discusses the five major constituents of concrete: cement, water, rock, sand, and air. The amount of volume in a concrete mixture that each constituent typically occupies is illustrated in Figure 2. Students often ask why aggregates are included in concrete since the cement paste contributes to the strength of concrete. The Hamburger Helper Analogy aids in this discussion. One pound of hamburger meat for a family of four does not go very far; however, if hamburger helper is used with the hamburger meat, a much larger meal can be produced. Similarly, in concrete production aggregates are added to the cement paste as an economical filler producing a larger product at a lower cost. If aggregates were not added to concrete, the price for a standard concrete mixture would at least double based on the two mixtures having the same volume. Figure 3 shows students discussing the hamburger helper analogy during a class break.
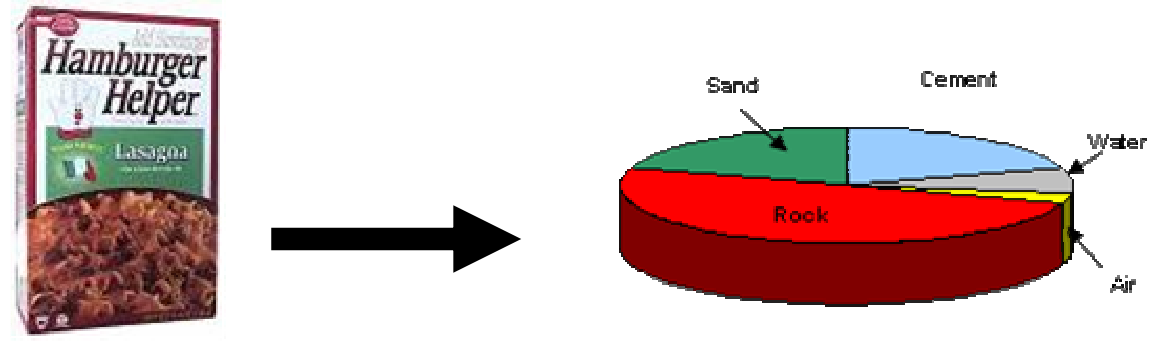

Figure 2. Aggregates Added as Economical Filler ${ }^{7}$ 


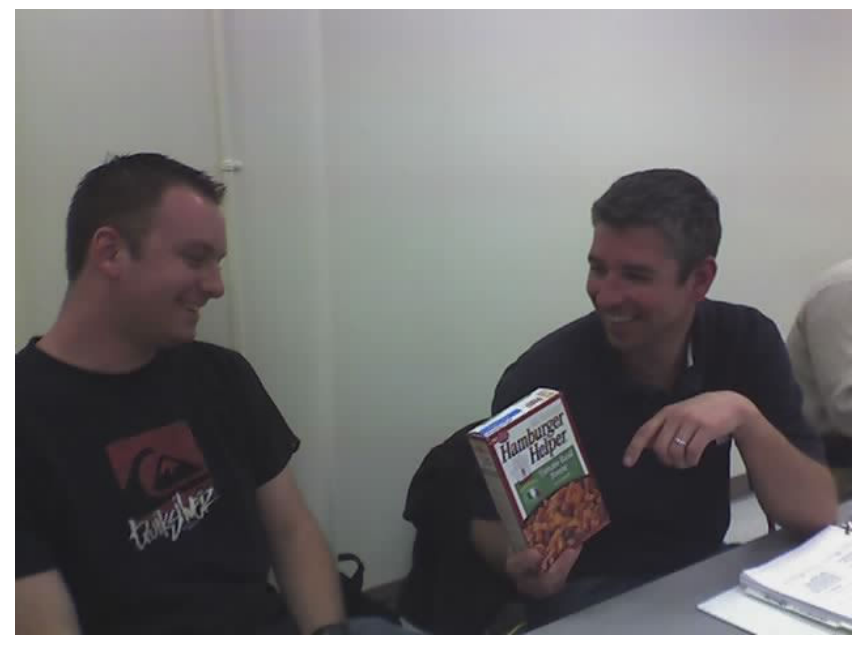

Figure 3. Students Discussing the Hamburger Helper Analogy

\section{Atomic Fireball Candy Experiment}

Cement hydration is often a difficult topic for students to understand. Cement hydration is defined as "the chemical reaction between the compounds of cement and water." exothermic reaction results in a certain amount of heat being produced during the reaction. Cement hydration will continue to some extent as long as moisture and heat are present. This reaction between water and cement can be demonstrated using the candy, Atomic Fireball. See Figure 4.

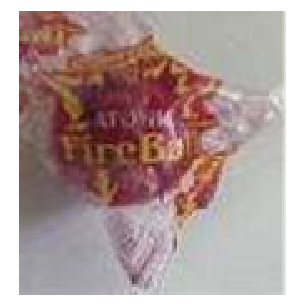

\section{Figure 4. Atomic Fireball Candy ${ }^{9}$}

Three comparisons can be made between the Atomic Fireball and cement hydration:

- Hydration reactions begin immediately once water touches the cement (the reaction of the atomic fireball begins immediately once it enters your mouth).

- Cement grains become smaller as hydration continues (the Atomic Fireball candy becomes smaller the longer it stays in your mouth).

- Hydration can continue as long as moisture and heat are present (the reaction of the Atomic Fireball continues as long as it stays in your mouth and until it dissolves).

The heat liberation curve for cement hydration resembles the heat given off by an atomic fireball. Figure 5 illustrates the heat given off during cement hydration and the five stages associated with cement hydration. 


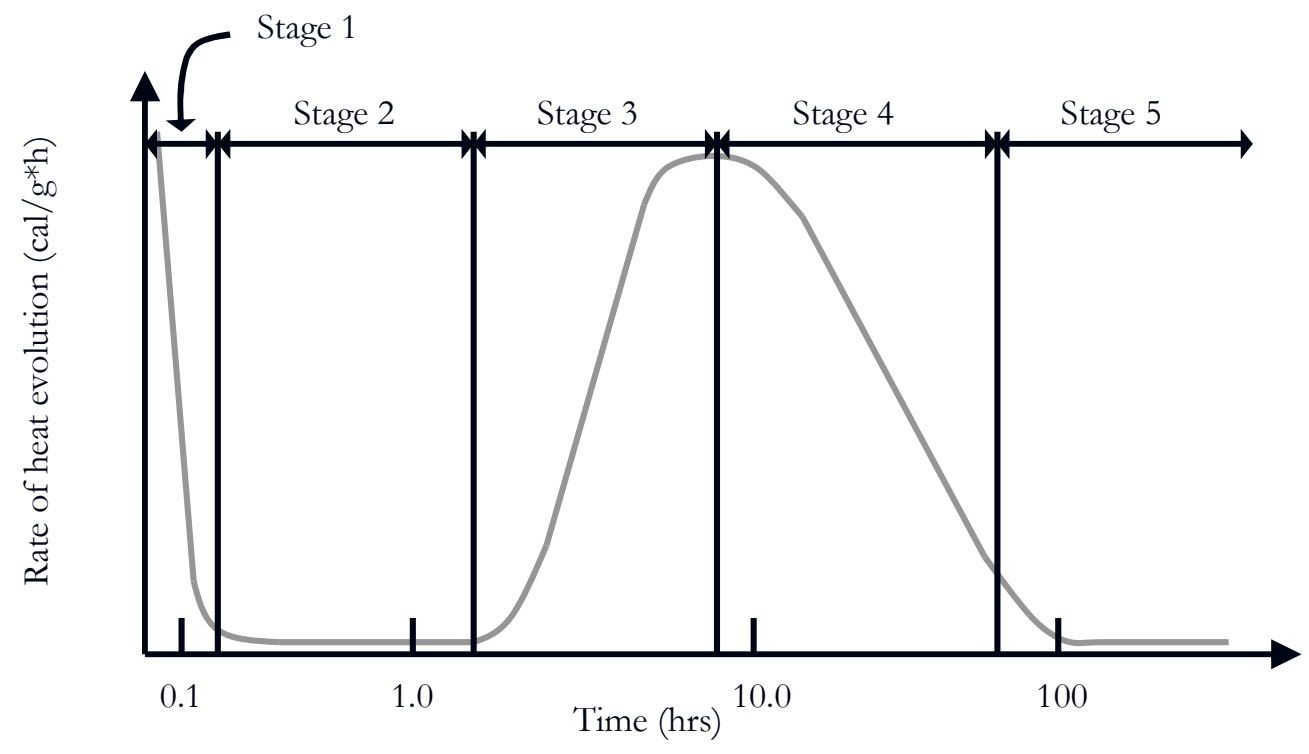

Figure 5. Heat Evolution During Cement Hydration

Stage 1 , initial hydrolysis, begins immediately when cement comes into contact with water. This stage experiences a rapid evolution of heat as seen when the Atomic Fireball is first placed in the mouth. After a period of time, Stage 2 (induction) begins where a low amount of heat that is released and the concrete remaining in the plastic state. The Atomic Fireball experiences this "leveling off" of heat once the outer surface of the candy is dissolved. The rate of heat evolution begins to accelerate during Stage 3. Similarly, the Atomic Fireball resumes giving off heat as a new layer within the candy is reached. The increased rate of heat evolution of cement hydration peaks and decelerates during Stage 4. Lastly, a steady state is reached in Stage 5 with low evolution of heat. Figure 6 shows a student examining the atomic fireball candy during the atomic fireball experiment.

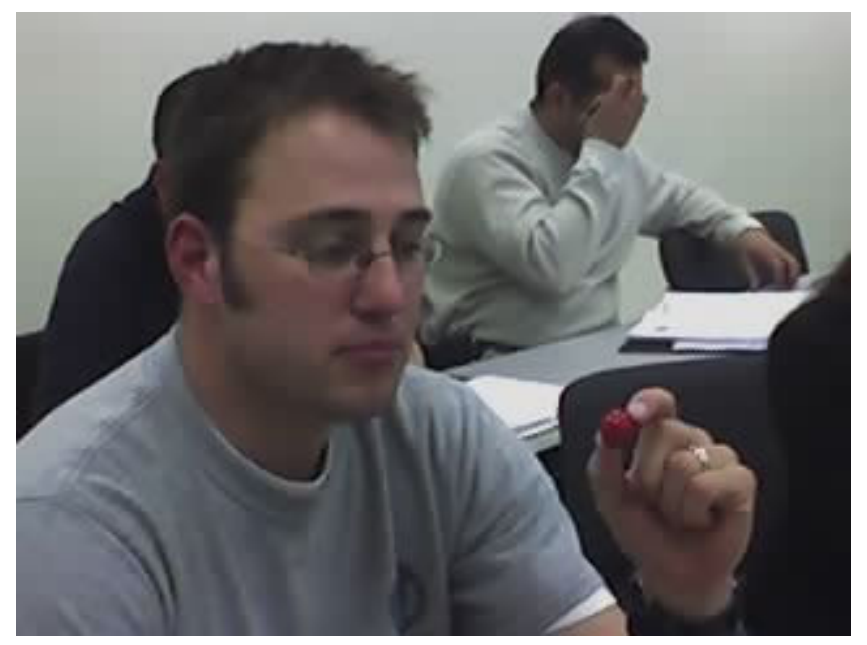

Figure 6. Student with the Atomic Fireball During the Class Experiment 


\section{Traffic Gridlock Analogy}

The stress-strain curve for steel can be described as "Traffic Gridlock on an Interstate." This analogy compares driving into a big city on the interstate with the stress versus strain relationship for steel, Figure 7. The stress versus strain diagram for steel contains four major areas of emphasis. These areas are described in regards to changes in the rate of stress and strain increase to one another. Strain is defined as the change in length of a material divided by the original length. For this analogy, strain is described as the change in driving distance in relation to the original starting place. Stress is defined as the applied load divided by the cross-sectional area of the material being tested. Stress as described in this analogy is the level of tension the driver experiences while driving into a big city. The initial portion [1] of the curve resembles slow moving traffic that produces large amounts of stress for drivers. In New York City, the regions of high stress increases and little strain changes would be the bridge crossings, where traffic always seems to move slowly. This portion of the stress-strain curve is normally referred to as the linear-elastic region of the curve. In this region the modulus of elasticity can be calculated. This is followed by a point on the curve or location on the interstate when traffic speed increases resulting in decreased stress and much greater strain or distance driving on the interstate [2]. This area of the curve produces a yield plateau, from where the yield strength of the steel is determined. Area [3] of the curve demonstrates strain hardening where mechanical strength is increased due to plastic deformation. This would resemble the slowing down of traffic as you approach a major interchange into a big city. This area will see an increased rate of stress and decreased strain. Finally, the steel specimen fails or the driver reaches their destination [4]. This analogy is meant to provide students with a way of understanding the changes in stress and strain of steel when subjected to load.

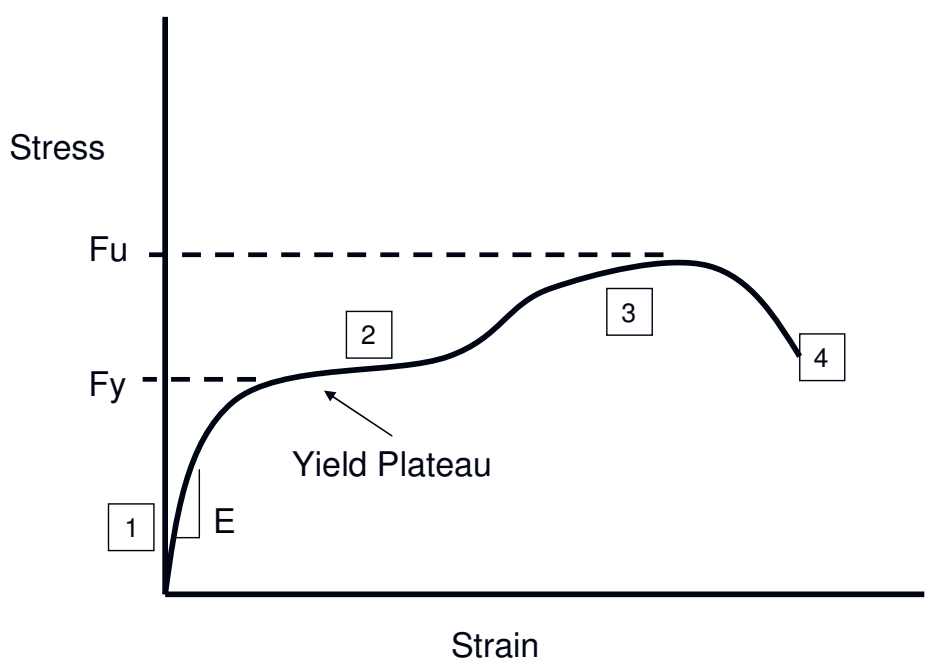

Figure 7. Typical Stress versus Strain Diagram for Steel

Straw Demonstration

Straws are an effective method of illustrating the structure of wood. Wood is composed of hollow tube-like cells that resemble a group of drinking straws, as shown in Figure 8. 

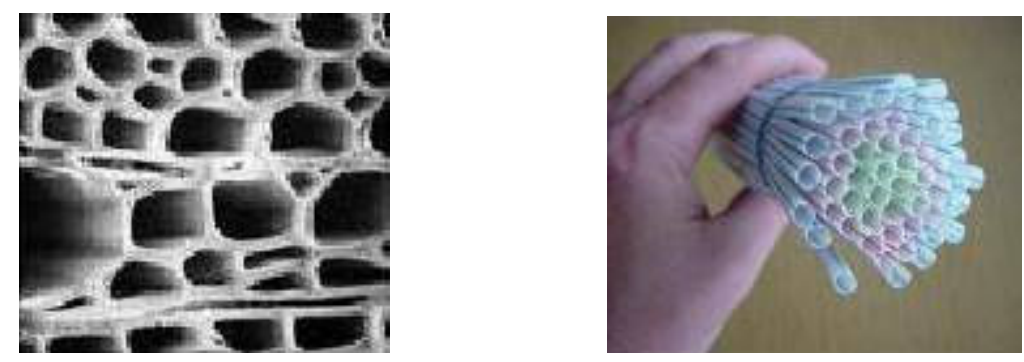

Figure 8. Comparison of Drinking Straws to Wood Structure ${ }^{10}$

This demonstration becomes valuable when discussing the behavior of wood under loads in different directions. Typically, wood testing can be performed by applying load parallel or perpendicular to the grain, see Figure 9. A student pulling straws "wood fibers" apart during the class demonstration is shown in Figure 10.

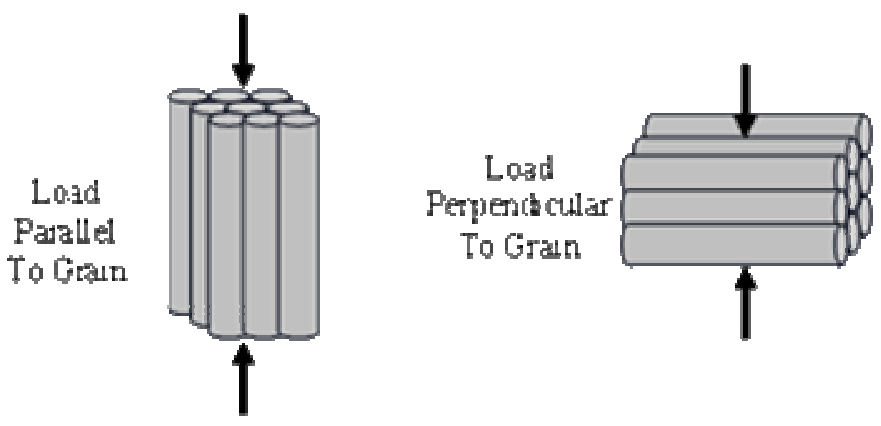

Figure 9. Testing Wood Parallel and Perpendicular to the Grain

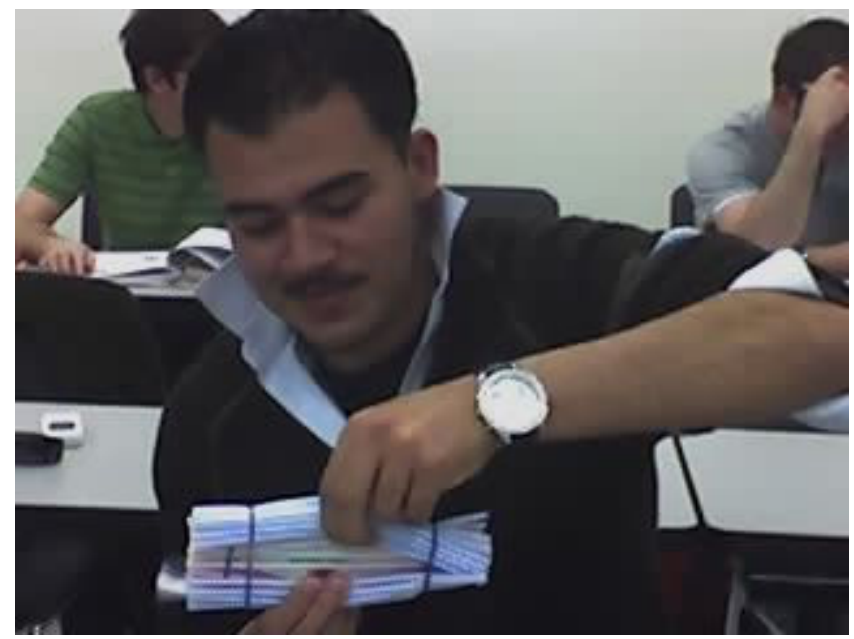

Figure 10. Student Pulling Straws "Wood Fibers" Apart While Examining Tension Perpendicular to the Grain 
The group of straws act as a visual demonstration of how wood is notably stronger when subjected to loads parallel to the grain than perpendicular. In addition, the manner in which the wood cells (straws) fail is also comparable. This comparison is listed in Table 1.

\section{Water-to-Cement Ratio Experiment}

A laboratory experiment can be conducted to evaluate the effect of changing the water-to-cement ratio $(\mathrm{w} / \mathrm{c})$ on concrete properties. The most notable affect $\mathrm{w} / \mathrm{c}$ has on concrete properties is compressive strength. Typically, as the w/c increases $(0.40 \rightarrow 0.70)$, the concrete compressive strength decreases. This is observed by having four laboratory groups each create a mixture with a different w/c. The mixture proportions used by the authors are shown in Table 2. Each group batches their mixture and observes workability of the mixture. In addition, 4"x8" cylinders are cast to test the compressive strength at 2 and 7 days of age. The students then gather the data and produce a compressive strength versus w/c curve. See Figure 11. This laboratory experiment provides the students with an opportunity to observe and test concrete at varying water contents.

Table 1. Straw Demonstration for Loading Wood in Different Directions

\begin{tabular}{|c|c|c|c|}
\hline $\begin{array}{l}\text { Type of } \\
\text { Test }\end{array}$ & Demonstration & $\begin{array}{c}\text { Wood } \\
\text { Failure Type }\end{array}$ & $\begin{array}{c}\text { Straw } \\
\text { Failure Type }\end{array}$ \\
\hline Compression & & $\begin{array}{l}\text { Failure caused by local } \\
\text { buckling and crushing of } \\
\text { cells. Large deformations at } \\
\text { failure. }\end{array}$ & $\begin{array}{l}\text { Straws will begin to } \\
\text { bend at middle and } \\
\text { separate from one } \\
\text { another. }\end{array}$ \\
\hline Tension & & $\begin{array}{l}\text { Failure occurs by breaking } \\
\text { bonds with fibers. Small } \\
\text { deformations occur prior to } \\
\text { failure. }\end{array}$ & $\begin{array}{l}\text { Straws are strongest } \\
\text { when demonstrated } \\
\text { in this manner. }\end{array}$ \\
\hline Compression & & $\begin{array}{l}\text { Failure occurs from } \\
\text { collapsing of cells. Extremely } \\
\text { large deformations at failure. }\end{array}$ & $\begin{array}{l}\text { Straws will totally } \\
\text { collapse leaving no } \\
\text { voids. }\end{array}$ \\
\hline Tension & $\downarrow$ & $\begin{array}{l}\text { Failure by breaking bonds } \\
\text { between cells. Large } \\
\text { deformations at failure. }\end{array}$ & $\begin{array}{l}\text { Straws will pull apart } \\
\text { from one another. }\end{array}$ \\
\hline
\end{tabular}

Table 2. Mixture Proportions for W/C Experiment

\begin{tabular}{|c|c|c|c|c|}
\hline w/c & Cement (lb) & Rock (Ib) & Sand (lb) & Water (Ib) \\
\hline 0.40 & 7.0 & 20.4 & 13.4 & 2.8 \\
\hline 0.50 & 7.0 & 20.4 & 11.6 & 3.5 \\
\hline 0.60 & 7.0 & 20.4 & 9.8 & 4.2 \\
\hline 0.70 & 7.0 & 20.4 & 8.0 & 4.9 \\
\hline
\end{tabular}




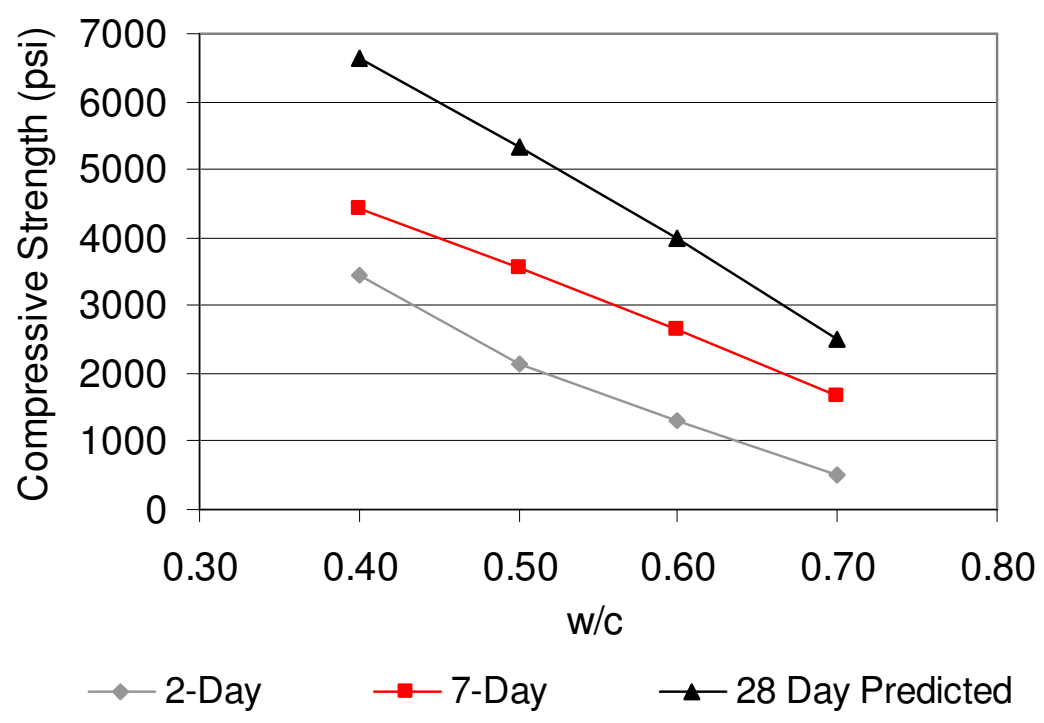

Figure 11. Compressive Strength versus W/C

Students will often comment on how the addition of water increases the fluidity of the concrete mixtures. This is shown in Figure 12. Students typically account in their laboratory reports how the lower w/c concrete mixtures are more difficult to compact in the cylinder molds than the higher w/c mixtures.

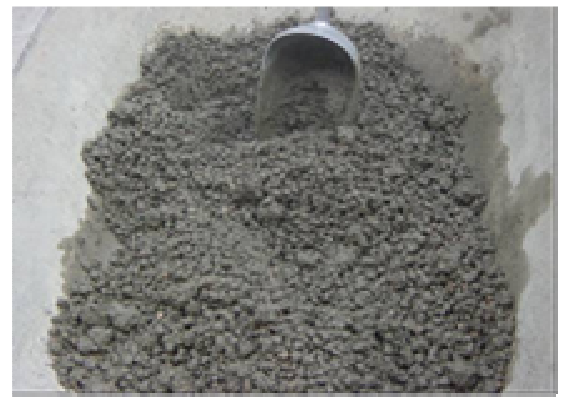

(a)

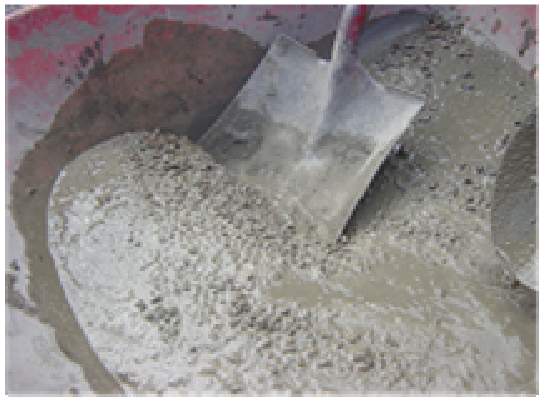

(b)

Figure 12. Comparison Between (a) 0.40 and (b) $0.60 \mathrm{~W} / \mathrm{C}$ Mixtures

This experiment also has a "real world" portion. Students are asked to provide cases where 0.40 , 0.50 , and $0.60 \mathrm{w} / \mathrm{c}$ concrete mixtures would be used in engineering practice. This provides an opportunity for students to research engineering projects and determine what $\mathrm{w} / \mathrm{c}$ is frequently used for certain structures (bridge beams, highway pavements, sidewalks, etc...).

\section{Concrete Curing Experiment}

The concrete curing experiment is a laboratory exercise in which four different curing treatments for concrete are analyzed. The curing regimens used for this experiment:

- moist curing in a water filled tank 
- dry curing in the laboratory

- ambient curing outside the laboratory

- box curing with insulation

Students cast thirty-six 4" $\mathrm{x} 8$ " concrete cylinders to be used to determine the compressive strength. Each curing regimen consists of nine cylinders, of which three cylinders are tested and averaged at 1, 14, and 28 days of age. The overall objective of this laboratory experiment is to demonstrate the significance of moist curing. Moist curing promotes continued hydration of the cement, thereby producing higher strength than air cured concrete. In addition, when cylinders are cured at elevated temperatures, the early age strengths are typically higher than other curing methods. This is demonstrated by curing cylinders in an insulated box that traps the heat given off by the cylinders.

Figure 13 illustrates the trends that are typically recognized by the students during this experiment. These trends include:

- The box-cured concrete cylinders produce almost double the strength when compared to cylinders of the other three methods at one day of age.

- The moist-cured concrete cylinders experience the highest compressive strength at 28 days of age.

- The ambient and dry-cured cylinders are similar in strength at 1, 14, and 28 days of age.

Concrete Compressive Strength vs. Age

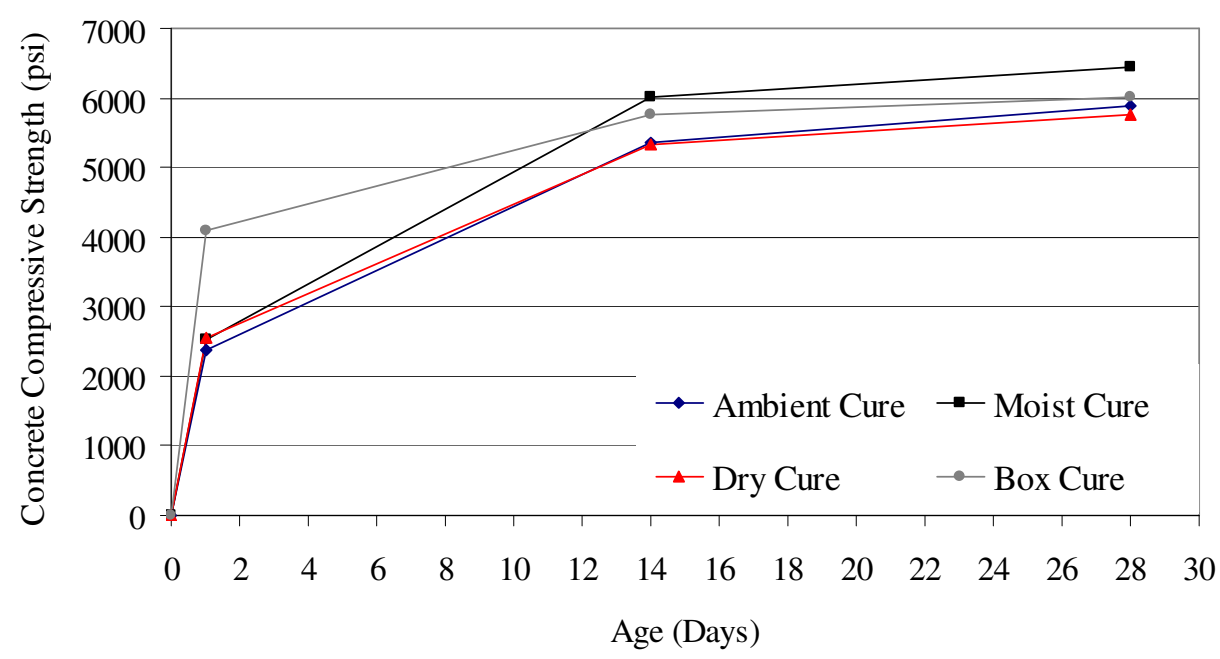

Figure 13. Concrete Curing Experiment Results 


\section{Teaching Aids and Bloom's Taxonomy}

Two of the learning types as described by Bloom's Taxonomy are experienced with the teaching aids discussed in this paper: cognitive and affective ${ }^{11,12}$. The cognitive learning type includes the development of cerebral skills. This type contains the knowledge, comprehension, and application of concepts from the teaching aids discussed in this paper. Each of the teaching aids describes a specific relationship between an object used for the analogy or experiment and a construction materials behavior. For example the straw demonstration is used to teach the students how wood behaves when subjected to loads parallel and perpendicular to the grain. The student through examination must demonstrate their understanding of these topics by summarizing each of the teaching aids discussed. Students will apply these concepts in future design classes when designing structures using concrete, steel, and wood.

The students also experience an affective type of learning with these teaching aids. This is demonstrated by the excitement and attentiveness during the class demonstrations and experiments. In addition, several of the teaching aids involve classroom participation such that the students are able to respond to what is physically happening. For example the students can physically feel the atomic fireball getting hotter in their mouth. The students are then able to relate this feeling to the concepts of cement hydration.

\section{Assessment}

The effectiveness of these visual aids, demonstrations, analogies, and experiments were based on how well students performed on related questions given on the final exam in a junior level materials course at the University of Colorado Denver (UCD).

A comprehensive final exam consisting of approximately 40 to 50 questions was given to the undergraduate construction materials course. Five questions related to the teaching aids discussed in this paper were included on the final exam in four consecutive semesters. Table 3 provides the teaching aid utilized, final exam question, class average on each question, and average over four semesters. The results of this assessment demonstrate that the Dice and Marble Analogy and Atomic Fireball Candy Experiment were extremely effective, with a four semester average grade above 90\%. In addition, the Hamburger Helper Analogy and Straw Demonstration teaching aids, though not as effective as the previous two, did receive a four semester average above the final exam grade average.

Students were required to submit a laboratory report on the results of the Water-to-Cement Ratio Experiment. Students were required to comment on the performance of the various mixtures. The four semester average for this report is $86 \%$. It should be noted that the reports were graded not only on technical content, but proper grammar and report format. 
Table 3. Assessment of Teaching Aids and Laboratory Techniques

\begin{tabular}{|c|c|c|c|c|c|c|}
\hline $\begin{array}{l}\text { Teaching Aid/ } \\
\text { Demonstration }\end{array}$ & Final Exam Questions & SP06 & F06 & SP07 & F07 & $\begin{array}{l}\text { Average } \\
\text { Score }\end{array}$ \\
\hline \multicolumn{2}{|c|}{ Number of Students Taking Course } & 25 & 28 & 15 & 20 & \\
\hline \multirow{2}{*}{$\begin{array}{l}\text { Dice and Marble } \\
\text { Analogy }\end{array}$} & $\begin{array}{l}\text { When used in concrete, which aggregate shape is } \\
\text { easiest to place and why? }\end{array}$ & $94 \%$ & $96 \%$ & $100 \%$ & $100 \%$ & $98 \%$ \\
\hline & $\begin{array}{l}\text { When used in concrete, which aggregate shape } \\
\text { privides the best bond between the aggregate and } \\
\text { cement paste and why? }\end{array}$ & $90 \%$ & $98 \%$ & $95 \%$ & $100 \%$ & $96 \%$ \\
\hline $\begin{array}{l}\text { Hamburger Helper } \\
\text { Analogy }\end{array}$ & $\begin{array}{l}\text { I stated in class that "Aggregatees are like } \\
\text { Hamburger Helper." Explain this analogy. }\end{array}$ & $88 \%$ & $93 \%$ & $73 \%$ & $95 \%$ & $87 \%$ \\
\hline $\begin{array}{l}\text { Atomic Fireball } \\
\text { Candy Experiment }\end{array}$ & $\begin{array}{c}\text { Cement hydration can continue as long as } \\
\text { and __ are present. }\end{array}$ & $80 \%$ & $98 \%$ & $90 \%$ & $95 \%$ & $91 \%$ \\
\hline $\begin{array}{l}\text { Straw } \\
\text { Demonstration }\end{array}$ & $\begin{array}{l}\text { When a wood specimen is subjected to tensile } \\
\text { forces to the grain, it is found to have the } \\
\text { greatest of all strength characteristics. }\end{array}$ & $88 \%$ & $89 \%$ & $67 \%$ & $100 \%$ & $86 \%$ \\
\hline \multicolumn{2}{|c|}{ Final Exam Grade Average } & $80 \%$ & $80 \%$ & $81 \%$ & $81 \%$ & $81 \%$ \\
\hline Experimentation & Lab Report & SP06 & F06 & SP07 & F07 & $\begin{array}{c}\text { Average } \\
\text { Score }\end{array}$ \\
\hline $\begin{array}{l}\text { Water-to-Cement } \\
\text { Ratio Experiment }\end{array}$ & $\begin{array}{l}\text { Lab \#3 - Examining the Effects of W ater/Cement on } \\
\text { Compressive Strength }\end{array}$ & $90 \% *$ & $90 \% *$ & $83 \% \%^{*}$ & $79 \% *$ & $86 \%{ }^{*}$ \\
\hline
\end{tabular}

* This includes the grading of both technical understanding of the lab and writing skills.

\section{Student Feedback}

The analogies and experiments discussed in this paper have proved to be successful in relating familiar items to engineering materials and concepts. Students have commented on how these teaching aids have helped them learn and retain knowledge regarding difficult topics in the civil engineering materials class. A few comments from former students are found below:

"The teaching techniques used in the materials lab were unforgettable. Every time I think of a concrete mix design I will think of hamburger helper. The one that was the most memorable is the heat of hydration process and how it exactly correlates with Atomic Fireballs. Another very important aspect of these learning techniques is that it makes learning fun." - Stephanie Spencer, junior civil engineering student at UCD, Fall 2006.

"The atomic fireball is truly inspired! It's fun, the image is strong, and it stays with you as a mnemonic of the setting process." - Chuck Wheat, graduated civil engineering at UCD, Fall 2006.

"I would like to say that your methods of teaching are by far the most effective I have ever experienced and it always helped me remember even until now. As far as the list starting with Hamburger Helper Analogy: it helped me remember that aggregate is just fillers and cheap, Atomic Fireball Experiment, was the best worst feeling to remember cement hydration, Traffic Gridlock Analogy still helps me determine the,$\sigma$ and $\varepsilon$ relationship and the group of straws helped me remember which way the wood is stronger." - Roxana Taghizadeh, junior civil engineering student at UCD, Fall 2006. 
"Let me respond by mentioning the fact that I can no longer walk down the grocery store aisle and look at a box of Cheesy Macaroni Hamburger Helper and not think about concrete. As Civil Engineering students we are bombarded with chalkboards of derivations, differential equations and textbook pages that sometimes appear as a foreign language. Taking some of these engineering principles and relating them to common items is helpful in understanding concepts." - Jim Fox, senior civil engineering student at UCD, Fall 2006.

"My favorite is the hamburger helper because it's easy to relate to and provides a good laugh (sticks in my mind), and the atomic fireball because you are able to experience it. I don't think that I'll forget either one." - Josh Powell, junior civil engineering student at UCD, Spring 2007.

"The hamburger helper analogy helped a lot and was a really good example. Traffic Gridlock is also good. Group of straws is also excellent. Those three examples are stuck in my head and I understand it very well. Last week when my Timber Design professor talked about wood for 30 seconds, all he talked about is wood being like a bunch of straws. If weren't for mechanics of material's lab, I would not know what he is talking about”. - Hiep Nguyen, senior civil engineering student at UCD, Spring 2007.

\section{Conclusion}

The authors have used the teaching aids presented in this paper as an effective method of explaining and demonstrating difficult topics in materials engineering. In addition, the laboratory experiments discussed by the authors provide students with the opportunity to observe factors that affect properties of concrete. Students have performed well on final exam questions pertaining to the topics discussed in this paper. Students have often commented on the benefits of these teaching aids, particularly how they relate common items to more technical topics in structural materials and materials testing. Furthermore, the visual aids, in-class experiments, and laboratory experiments present information in a way that provides students with a great learning experience.

\section{Bibliography}

1. Davis, S. (2007) "Learning Styles and Memory," Institute for Learning Styles Journal, Vol. 1, Fall 2007. pp. 4651.

2. Rosati, P. (1998). “The Learning Preferences of Engineering Students from Two Perspectives," Proc. 1998 Frontiers in Education Conference, Nov. 4-7, 1998, Tempe AZ.

3. Felder R.M. and Spurlin, J. (2005). "Applications, Reliability, and Validity of the Index of Learning Styles," International Journal of Engineering Education. Vol. 21, No. 1., pp. 103-112.

4. Mamlouk, M.S. and Zaniewski, J.P. (2006). Materials for Civil and Construction Engineers, $2^{\text {nd }}$ Edition. Pearson Education, Inc., Pearson Prentice Hall. Upper Saddle River, NJ.

5. Dice (2007). http://wilderdom.com/images/dice.gif Accessed June 10, 2007. 
6. Marbles (2007). http://www.photoblogster.com/images/20060211182945_marbles.jpg Accessed June 10, 2007.

7. Hamburger Helper (2007). http://www.wackypackages.org/realproductsscans/2005/hamburgerhelper.jpg Accessed June 10, 2007.

8. Somayaji, S. (2001). Civil Engineering Materials, $2^{\text {nd }}$ Edition. Prentice Hall. Upper Saddle River, NJ.

9. Atomic Fireball (2007). www.lincolnpennycandy.com Accessed June 10, 2007

10. Wood Cells (2007). www.timber.org.au Accessed June 14, 2007.

11. Taxonomy of Educational Objectives (2008). http://en.wikipedia.org/wiki/Taxonomy_of_Educational_Objectives\#Affective Accessed February 27, 2008.

12. Krathwohl, D.R. (2002). “A Revision of Bloom's Taxonomy: An Overview,” Theory into Practice, Volume 41, No. 4, Copyright 2002 College of Education, The Ohio State University. Fall 2002. 